\title{
Commentary: Smoke on the clotter
}

\author{
John Bozinovski, MD, MSc
}

From the Division of Cardiac Surgery, The Ohio State University Wexner Medical Center, Columbus, Ohio. Disclosures: Author has nothing to disclose with regard to commercial support.

Received for publication Sept 23, 2019; revisions received Sept 23, 2019; accepted for publication Sept 23, 2019; available ahead of print Oct 3, 2019

Address for reprints: John Bozinovski, MD, MSc, Division of Cardiac Surgery, The Ohio State University Wexner Medical Center, N816A Doan Hall, 410 West 10th Ave, Columbus, OH 43210 (E-mail: jovan.bozinovski@ osumc.edu).

J Thorac Cardiovasc Surg 2020;160:1232-3

$0022-5223 / \$ 36.00$

Copyright (c) 2019 by The American Association for Thoracic Surgery

https://doi.org/10.1016/j.jtcvs.2019.09.094

Beller and colleagues examined anticoagulant (AC) use following cardiac surgery ${ }^{1}$ by examining a subset of the Society of Thoracic Surgery database. The study does not provide evidence to guide choices; rather, it describes what we are actually doing for postoperative patients. By shedding light on past practices, it will alter the way we currently practice. Looking at 2 time periods (2011-2014 and 20152018), the authors found AC use to be stable overall but that the proportion of patients receiving non-vitamin $\mathrm{K}$ oral AC (NOAC) has increased. This increase in preference for a NOAC, over a vitamin $\mathrm{K}$ antagonist (VKA), is most pronounced in the biologic aortic valve replacement cohort but was still dramatic in the biologic mitral valve and coronary artery bypass cohorts. A strength of the study was the large number of patients examined, the focus on type of AC used, and the subgroups examined.

Use of NOAC as the AC of choice overall increased to $35 \%$ in the more current period examined (2015-2018), but in those receiving $\mathrm{AC}$ for biologic valves as the only putative indication (the study was unable to ascertain for certain the indication for AC use), we still prescribe VKA much more commonly $(86.9 \%$ of the time or a ratio of $6.6: 1)$, but even here use of NOAC increased over the 2 periods.

It remains controversial whether to anticoagulate biologic valves, not to mention what should be the duration of therapy, or agent of choice, if pursued. We are aware that the American College of Cardiology/American Heart Association guidelines regarding this are largely ignored, as evidenced by the study of Beller and colleagues. ${ }^{1}$ Of the biologic valves, $68 \%$ did not receive AC postoperatively. Of the $32 \%$ of biologic valves that did receive $\mathrm{AC}$ postoperatively, $80 \%$ had other indications for AC, including atrial fibrillation or venous thromboembolism. Excluding these latter patients, and assuming the $68 \%$ of patients not getting AC had no other indication for $\mathrm{AC}$, only 745 of the 8684 patients $(8.5 \%)$ with biologic valves without other indication for AC received AC. This 8.5\% of patients demonstrates that we as a community have limited faith in the American College of Cardiology/

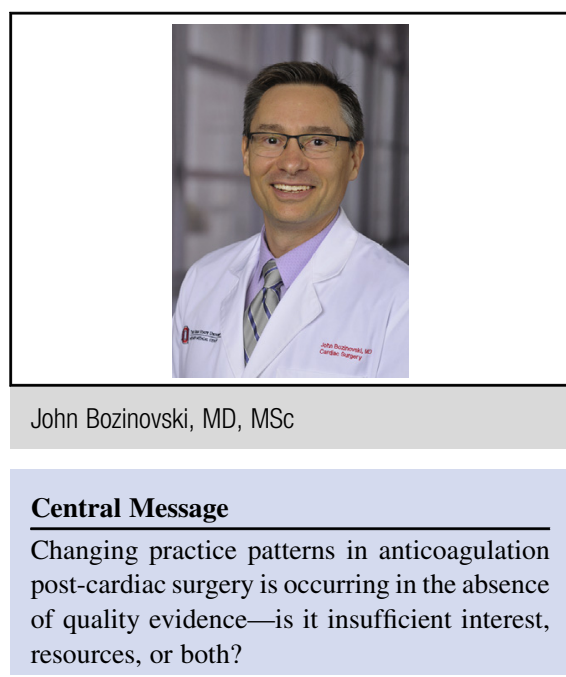

See Article page 1222.

American Heart Association guidelines ${ }^{2,3}$ on this topic. Why is this so, when it is a Class IIa, Level of Evidence $\mathrm{B}$ recommendation?

There may be many reasons for this, including our faith in the quality of evidence used to make the recommendations and the presence of conflicting evidence. The supporting evidence for anticoagulation in biologic aortic valve replacement in the 2014 guidelines $^{2}$ includes 6 citations, of which one is an editorial, ${ }^{4} 3$ suggested no benefit for $\mathrm{AC},{ }^{5-7}$ one of which is the only randomized control trial, ${ }^{5}$ and 2 suggested benefit. ${ }^{8,9}$ In one that suggested benefit there was, paradoxically, a 2.3-fold increase in the rate of bleeding without VKA. ${ }^{8}$ The 2017 update of the guidelines ${ }^{3}$ used more compelling studies favoring $\mathrm{AC}^{10,11}$ but no randomized control trial.

The study of Beller and colleagues highlights that we are instituting practice patterns in the absence of quality evidence and despite moderately good evidence, essentially hoping that we are doing the right thing. Anticoagulation for biologic valves is an issue that has been debated for decades, and calls for the need for a prospective randomized trial on the subject have become reflexive clinical science etiquette without consequence. We are blowing smoke when what we need is to light a fire.

\section{References}

1. Beller JP, Krebs ED, Hawkins RB, Mehaffey H, Quader MA, Speir AM, et al Non-vitamin K oral anticoagulant use after cardiac surgery is rapidly increasing. J Thorac Cardiovasc Surg. 2020;160:1222-31.

2. Nishamura RA, Otto CM, Bonow RO, Carabello BA, Erwin JP, Guyton RA, et al. 2014 AHA/ACC guideline for the management of patients with valvular heart 
disease: a report of the American College of Cardiology/American Heart Association task force on practice guidelines. J Thorac Cardiovasc Surg. 2014;148: e1-132.

3. Nishimura RA, Otto CM, Bonow RO, Carabello BA, Erwin JP III, Fleisher LA, et al. 2017 AHA/ACC focused update of the 2014 AHA/ACC guideline for the management of patients with valvular heart disease: a report of the American College of Cardiology/American Heart Association task force on clinical practice guidelines. Circulation. 2017;135:e1159-95.

4. Mehta SR, Weitz JI. Editorial—warfarin after bioprosthetic aortic valve implantation. JAMA. 2012;308:2147-8.

5. Aramendi JI, Mestres D-A, Martinz-Leon J, Campos V, Munoz G, Navas C. Trifusal versus oral anticoagulation for primary prevention of thromboembolism after bioprosthetic valve replacement (trac): prospective, randomized, co-operative trial. Eur J Cardiothorac Surg. 2005;27:854-60.

6. Sundt TM, Zehr KJ, Dearani JA, Daly RC, Mullany CJ, McGregor CG, et al. Is early anticoagulation with warfarin necessary after bioprosthetic aortic valve replacement? J Thorac Cardiovasc Surg. 2005;129:1024-31.
7. El Bardissi AW, DiBardino DJ, Chen FY, Yamashita MH, Cohn LH. Is early antithrombotic therapy necessary in patients with bioprosthetic aortic valves in normal sinus rhythm? J Thorac Cardiovasc Surg. 2010;139:1137-45.

8. Heras M, Chesebro JH, Fuster V, Penny WJ, Grill DE, Bailey KR, et al. High risk of thromboemboli early after bioprosthetic cardiac valve replacement. J Am Coll Cardiol. 1995;25:1111-9.

9. Mérie C, Køber L, Skov Olsen P, Andersson C, Gislason G, Skov Jensen J, et al. Association of warfarin therapy duration after bioprosthetic aortic valve replacement with risk of mortality, thromboembolic complications, and bleeding. JAMA 2012;308:2118-25

10. Brennan JM, Edwards FH, Zhao Y, O'Brien S, Booth ME, Dokholyan RS, et al Early anticoagulation of bioprosthetic aortic valves in older patients: results from the Society of thoracic surgeons adult cardiac surgery national database. J Am Coll Cardiol. 2012;60:971-7.

11. Egbe AC, Pislaru SV, Pellikka PA, Peterucha JT, Schaff HV, Maleszewski JJ, et al. Bioprosthetic valve thrombosis versus structural failure: clinical and echocardiographic predictors. J Am Coll Cardiol. 2015;66:2285-94. 